\title{
BMJ
}

\section{The views of patients and carers in treatment decision making for chronic kidney disease: systematic review and thematic synthesis of qualitative studies}

\section{R L Morton, research fellow in health economics, ${ }^{1} \mathrm{~A}$ Tong, research fellow in qualitative research, ${ }^{1,2} \mathrm{~K}$ Howard, senior lecturer in health economics, ${ }^{1}$ P Snelling, director of dialysis, nephrologist, ${ }^{3}$ A C Webster, senior lecturer in clinical epidemiology, nephrologist ${ }^{1,2}$}

Sydney School of Public Health, University of Sydney, Sydney, NSW 2006, Australia

${ }^{2}$ Centre for Kidney Research, The Children's Hospital at Westmead, NSW

${ }^{3}$ Department of Renal Medicine, Royal Prince Alfred Hospital, Camperdown, NSW

Correspondence to: R L Morton rachaelm@health.usyd.edu.au

Cite this as: BMJ 2010;340:c112 doi:10.1136/bmi.c112

\section{ABSTRACT}

Objective To synthesise the views of patients and carers in decision making regarding treatment for chronic kidney disease, and to determine which factors influence those decisions.

Design Systematic review of qualitative studies of decision making and choice for dialysis, transplantation, or palliative care, and thematic synthesis of qualitative studies.

Data sources Medline, PsycINFO, CINAHL, Embase, social work abstracts, and digital theses (database inception to week 3 October 2008) to identify literature using qualitative methods (focus groups, interviews, or case studies).

Review methods Thematic synthesis involved line by line coding of the findings of the primary studies and development of descriptive and analytical themes.

Results 18 studies that reported the experiences of 375 patients and 87 carers were included. 14 studies focused on preferences for dialysis modality, three on transplantation, and one on palliative management. Four major themes were identified as being central to treatment choices: confronting mortality (choosing life or death, being a burden, living in limbo), lack of choice (medical decision, lack of information, constraints on resources), gaining knowledge of options (peer influence, timing of information), and weighing alternatives (maintaining lifestyle, family influences, maintaining the status quo).

Conclusions The experiences of other patients greatly influenced the decision making of patients and carers. The problematic timing of information about treatment options and synchronous creation of vascular access seemed to predetermine haemodialysis and inhibit choice of other treatments, including palliative care. A preference to maintain the status quo may explain why patients often remain on their initial therapy.

\section{INTRODUCTION}

Clinical guidelines in the United States, Canada, United Kingdom, Europe, and Australasia recommend that treatment options for chronic kidney disease include the preference of a fully informed patient. ${ }^{1-3}$ In the UK alone, 7000 patients a year progress to end stage kidney disease requiring transplantation, dialysis, or "supportive non-dialytic" (palliative) care. ${ }^{4}$ For most of these patients progression to end stage kidney disease can be anticipated, enabling patients' preferences for treatment to be incorporated into their care. Recent data from observational studies and the US Renal Data System, however, suggest that patients with chronic kidney disease may not be presented with adequate information on treatment options or given sufficient time in which to discuss management alternatives with their families or carers. ${ }^{5-8}$ Low rates of kidney transplantation in patients on low incomes and those from minority ethnic groups also suggest that patient and family preferences are not being taken into account. $^{9-11}$

Although large numbers of patients with chronic kidney disease exist worldwide, data on the factors that influence preferences for treatment from a patient or carer perspective are limited. Qualitative research methods used in focus groups or in-depth interviewing have the advantage of reporting the attitudes, feelings, and beliefs of patients, allowing readers some insight into their perspective. A synthesis of findings from several qualitative studies in chronic kidney disease has the ability to achieve a greater conceptual understanding of the topic beyond a single empirical study. ${ }^{12}$ Thematic synthesis, as first described in $1988,{ }^{13}$ draws on the findings of original studies and uses those findings as data in a subsequent analysis. This allows readers to appreciate what has been discovered, build on what is already known, and translate these findings into their own clinical practice. ${ }^{121415}$

Awareness of the factors associated with decision making in the treatment of chronic kidney disease can provide health professionals with evidence on how best to deliver education programmes for patients and their families; it may also enhance communication and improve the capacity for patient and family involvement in shared decision making. We synthesised and analysed the views of patients and their informal 


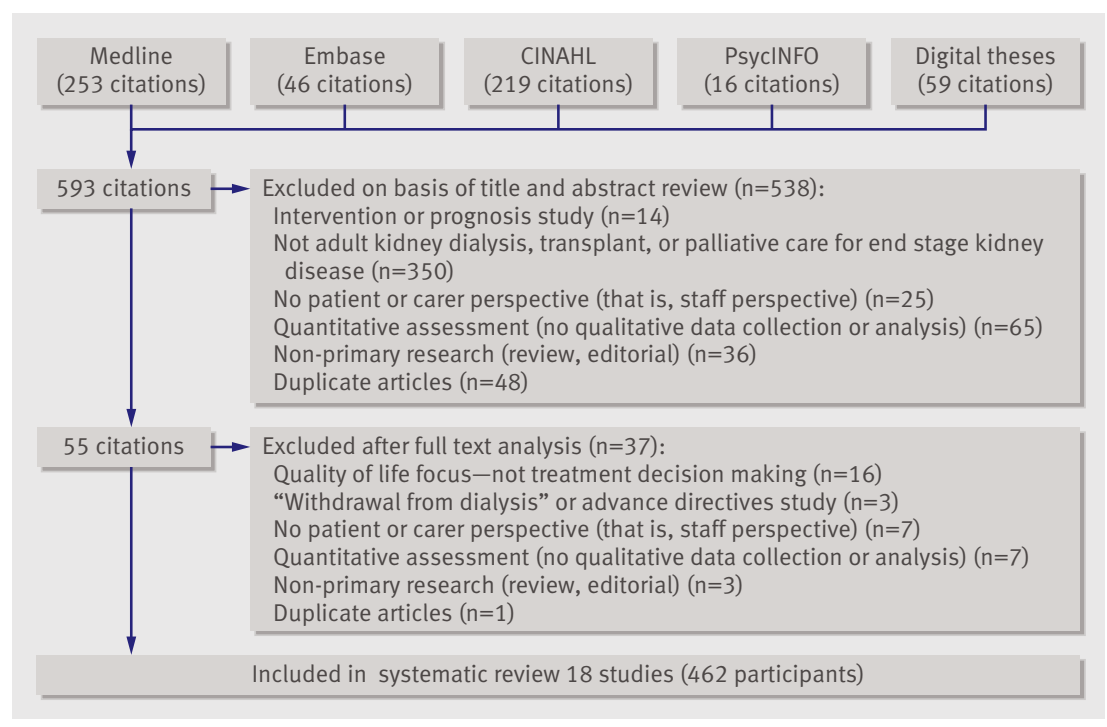

Fig 1| Results of search strategy and identification of publications included in review

carers on decision making in the treatment of chronic kidney disease and determined which factors influenced decisions about treatment.

\section{METHODS}

Thematic synthesis aims to achieve analytical abstraction at a higher level, by rigorously examining overlap and elements in common among studies. We used thematic synthesis to focus on patient and carer preferences, decision making, and choice for treatments in patients with chronic kidney disease. This methodology was chosen for two reasons. Firstly, it enabled the analysis of a substantive literature in decision making for all types of treatment for chronic kidney disease, as no single study provided perspectives on transplantation, haemodialysis, peritoneal dialysis, and palliative care. Secondly, it enabled the description of influencing factors on decision making for this population and the development of analytical themes that could be applied across therapies and diverse treatment settings.

\section{Selection criteria and literature search}

We included qualitative studies that used interviews, focus groups, or observations to explore patient and carer preferences for kidney dialysis modality, transplantation, or palliative care. A patient was defined as an adult with chronic kidney disease or end stage kidney disease. ${ }^{16}$ A carer was defined as someone related to or unrelated to, in a paid or unpaid role of supporting, someone receiving any form of treatment for chronic kidney disease (excluding health professionals). We excluded qualitative studies of "withdrawal from dialysis" or studies that focused solely on quality of life with dialysis or transplant. Non-English articles were excluded to prevent cultural and linguistic bias in translations. We excluded studies if they used structured questionnaires as the sole method for data collection, or reported only quantitative data. Studies that did not elicit data from patients or carers themselves were also excluded.
We combined MeSH terms and text words for renal replacement therapy, peritoneal dialysis, haemodialysis, kidney transplant, palliative care, and chronic kidney disease with terms relating to patients and caregivers and then combined them with MeSH terms and text words for preferences (choice, decision making, involvement, options) and text words for qualitative methods. Using a detailed search strategy (see web extra appendix 1) we carried out searches in Medline (1950 to October week 1 2008), PsycINFO (1806 to October week 1 2008), CINAHL (1982 to October week 1 2008), Embase (1980 to 2008), social work abstracts (1977 to October week 4), social science journals (1994 to October 2008), and EconLit (1960 to 2008). All titles in past issues of the Nephrology Nursing Journal, Qualitative Health Research, and Qualitative Research up to October 2008 were hand searched. We also searched electronic theses, reference lists of relevant studies, and reviews. The abstracts and studies were screened then discarded if they did not fit the selection criteria. Studies that seemed to include relevant data or information were retrieved and their full text versions analysed and examined for study eligibility.

\section{Comprehensiveness of reporting}

Two researchers (RLM and AT) independently assessed the reporting of selected studies using the consolidated criteria for reporting qualitative research (COREQ) framework, with disagreements resolved by discussion. ${ }^{17}$ The domains of this checklist (research team and reflexivity, study design, and data analysis and reporting) provide a transparency of research methods that allow readers to assess the trustworthiness and transferability of the findings of the primary study to their setting. ${ }^{18}$ Studies were not excluded or weighted on the basis of the quality of reporting assessment.

\section{Synthesis of findings}

Quotations from participants and text under the heading "results" or "findings" from each study were entered verbatim into Nvivo 8 software (QSR International, Melbourne, Australia) for storing, coding, and searching qualitative data. Thematic synthesis involved three phases: line by line coding of the findings of the primary studies, development of descriptive themes, and development of analytical themes. ${ }^{18}$ Each study was read several times to ensure that all the texts relating to patient and carer perspectives were integrated. The concepts were examined for similarities and differences and then grouped into a model structure of themes. ${ }^{19}$

\section{RESULTS}

The search yielded 593 citations. Of these, 538 were ineligible after review of the title and abstract (fig 1). Of the remaining 55 studies, 37 were excluded because they did not include a patient or carer assessment of decision making $(\mathrm{n}=7)$, contained quantitative assessment only $(\mathrm{n}=7)$, were not primary research $(n=3)$, featured a quality of life focus - that is, not treatment decision making $(n=16)$, were centred around 
Table 1|Characteristics of included studies

\begin{tabular}{|c|c|c|c|c|c|c|c|c|c|}
\hline Study & Country & Perspective & Treatment & $\begin{array}{l}\text { Total No of } \\
\text { participants* }\end{array}$ & $\begin{array}{l}\text { Response } \\
\text { rate (\%) }\end{array}$ & $\begin{array}{l}\text { Data } \\
\text { collection }\end{array}$ & Methodology $†$ & Analysis $†$ & $\begin{array}{c}\text { Principal experiences } \\
\text { explored }\end{array}$ \\
\hline Ashby $2005^{21}$ & Australia & $\begin{array}{l}\text { Patients, } \\
\text { spouses }\end{array}$ & Palliative & 12 & 30 & Interviews & Grounded theory & $\begin{array}{l}\text { Constant } \\
\text { comparative analysis }\end{array}$ & $\begin{array}{l}\text { End of life decision making, } \\
\text { effect on family, } \\
\text { communication with staff }\end{array}$ \\
\hline Bass $1999^{20}$ & US & Patients, staff & $\begin{array}{l}\text { Haemodialysis, peritoneal } \\
\text { dialysis }\end{array}$ & 13 & Not stated & Focusgroups & Not stated & Content analysis & $\begin{array}{l}\text { Freedom/control, quality of } \\
\text { life }\end{array}$ \\
\hline $\begin{array}{l}\text { Breckenridge } \\
1997^{22}\end{array}$ & US & $\begin{array}{l}\text { Patients, } \\
\text { spouses }\end{array}$ & $\begin{array}{l}\text { In-centre haemodialysis, } \\
\text { satellite or limited care } \\
\text { haemodialysis, } \\
\text { continuous ambulatory } \\
\text { peritoneal dialysis }\end{array}$ & 24 & Not stated & Interviews & Grounded theory & $\begin{array}{l}\text { Constant } \\
\text { comparative analysis }\end{array}$ & $\begin{array}{l}\text { Choice of treatment } \\
\text { modality, decision making }\end{array}$ \\
\hline Chen $2007^{35}$ & Taiwan & Patients & $\begin{array}{l}\text { Haemodialysis, peritoneal } \\
\text { dialysis }\end{array}$ & 30 & 94 & Interviews & Grounded theory & $\begin{array}{l}\text { Constant } \\
\text { comparative analysis }\end{array}$ & $\begin{array}{l}\text { Dialysis decision making, } \\
\text { adaptation }\end{array}$ \\
\hline Courts $2000^{23}$ & US & $\begin{array}{l}\text { Patients, } \\
\text { carers }\end{array}$ & Home haemodialysis & 14 & Not stated & $\begin{array}{l}\text { Survey, } \\
\text { interviews }\end{array}$ & Not stated & Not stated & $\begin{array}{l}\text { Reasons for choosing home } \\
\text { haemodialysis, carers' } \\
\text { experiences }\end{array}$ \\
\hline Feild $1996^{36}$ & US & Patients & $\begin{array}{l}\text { Transplant haemodialysis, } \\
\text { peritoneal dialysis }\end{array}$ & 16 & 62 & Interviews & Grounded theory & $\begin{array}{l}\text { Constant } \\
\text { comparative analysis }\end{array}$ & Treatment decision making \\
\hline $\begin{array}{l}\text { Fetherston- } \\
\text { haugh } 2007^{34}\end{array}$ & Australia & Patients & Chronic kidney disease & 21 & 72 & Interviews & Not stated & Thematic analysis & Dialysis decision making \\
\hline $\begin{array}{l}\text { Harwood } \\
2005^{24}\end{array}$ & Canada & Patients & Haemodialysis & 11 & 92 & Interviews & Not stated & Content analysis & $\begin{array}{l}\text { Stressors approaching end } \\
\text { stage kidney disease }\end{array}$ \\
\hline $\begin{array}{l}\text { Kelly-Powell } \\
1997^{25}\end{array}$ & US & Patients & $\begin{array}{l}\text { Haemodialysis, peritoneal } \\
\text { dialysis }\end{array}$ & 9 & Not stated & Interviews & Grounded theory & $\begin{array}{l}\text { Constant } \\
\text { comparative analysis }\end{array}$ & $\begin{array}{l}\text { Treatment decisions, } \\
\text { choices, carers' preferences }\end{array}$ \\
\hline $\begin{array}{l}\text { Landrenau } \\
2006^{27}\end{array}$ & US & Patients & $\begin{array}{l}\text { Transplant haemodialysis, } \\
\text { peritoneal dialysis }\end{array}$ & 6 & Not stated & Interviews & Phenomenology & $\begin{array}{l}\text { Phenomenological } \\
\text { analysis }\end{array}$ & $\begin{array}{l}\text { Choice, knowledge, } \\
\text { information received }\end{array}$ \\
\hline $\begin{array}{l}\text { Landrenau } \\
2007^{26}\end{array}$ & US & Patients & Haemodialysis & 12 & Not stated & Interviews & Phenomenology & $\begin{array}{l}\text { Phenomenological } \\
\text { analysis }\end{array}$ & $\begin{array}{l}\text { Knowledge, perceptions of } \\
\text { choice }\end{array}$ \\
\hline Lee $2008^{37}$ & Denmark & Patients & $\begin{array}{l}\text { Haemodialysis, peritoneal } \\
\text { dialysis, chronic kidney } \\
\text { disease }\end{array}$ & 45 & Not stated & Focusgroups & Not stated & Not stated & $\begin{array}{l}\text { Patient involvement in } \\
\text { modality choice, advantages } \\
\text { and disadvantages of } \\
\text { modalities }\end{array}$ \\
\hline Leung $2007^{32}$ & Hong Kong & $\begin{array}{l}\text { Donors, } \\
\text { recipients }\end{array}$ & Transplant & 12 & Not stated & Interviews & Exploratory & Content analysis & $\begin{array}{l}\text { Decision making for } \\
\text { transplantation, impact of } \\
\text { dialysis }\end{array}$ \\
\hline $\operatorname{Lin} 2005^{28}$ & Taiwan & Patients & Haemodialysis & 12 & Not stated & Interviews & Phenomenology & $\begin{array}{l}\text { Phenomenological } \\
\text { analysis }\end{array}$ & $\begin{array}{l}\text { Experience with } \\
\text { haemodialysis, information } \\
\text { seeking, decision making }\end{array}$ \\
\hline Trisolini $2004^{29}$ & US & $\begin{array}{l}\text { Patients, } \\
\text { family, staff }\end{array}$ & $\begin{array}{l}\text { Chronic kidney disease, } \\
\text { haemodialysis }\end{array}$ & 140 & Not stated & $\begin{array}{l}\text { Focus, } \\
\text { Interviews }\end{array}$ & Not stated & Thematic analysis & $\begin{array}{l}\text { Knowledge about options, } \\
\text { communication, role of } \\
\text { patient in treatment } \\
\text { decisions }\end{array}$ \\
\hline $\begin{array}{l}\text { Waterman } \\
2006^{33}\end{array}$ & US & $\begin{array}{l}\text { Donors, } \\
\text { recipients }\end{array}$ & Transplant & 33 & Not stated & Focusgroups & Not stated & Content analysis & $\begin{array}{l}\text { Decision making for } \\
\text { transplantation from living } \\
\text { donors }\end{array}$ \\
\hline $\begin{array}{l}\text { Whittaker } \\
1996^{30}\end{array}$ & US & Patients & $\begin{array}{l}\text { Continuous ambulatory } \\
\text { peritoneal dialysis, } \\
\text { haemodialysis }\end{array}$ & 20 & 95 & Interviews & Grounded theory & $\begin{array}{l}\text { Constant } \\
\text { comparative analysis }\end{array}$ & $\begin{array}{l}\text { Values, lifestyle, autonomy, } \\
\text { decision making }\end{array}$ \\
\hline Wuerth $2002^{31}$ & US & Patients & $\begin{array}{l}\text { Peritoneal dialysis, } \\
\text { haemodialysis }\end{array}$ & 40 & Not stated & Interviews & Not stated & Thematic analysis & $\begin{array}{l}\text { Factors influencing choice of } \\
\text { modality }\end{array}$ \\
\hline
\end{tabular}

"withdrawal from dialysis" rather than initiation of treatment $(n=3)$, or were repeat publications from the same study $(n=1)$. Eighteen studies including three unpublished theses were included in the review (table 1). ${ }^{20-37}$ These studies used focus groups or in-depth semistructured interviews from 375 patients with chronic kidney disease who were treated by kidney transplant, peritoneal dialysis, haemodialysis, or palliative care. Eighty seven informal carers or family members of the patients were also included. The studies were carried out in the United States, Canada, Denmark, Australia, Hong Kong, and Taiwan.

\section{Comprehensiveness of reporting of included studies}

The completeness of reporting was variable across the studies, with between 14 and 28 of the 32 items from the consolidated criteria for reporting qualitative research framework clearly documented (table 2). ${ }^{17}$ All 18 studies specified the sample size and characteristics of the participants. Seventeen included quotations from respondents in their results, and seven reported on the use of software to store, code, and search data. Only three reported on previous relationships with participants and none of the studies reported returning transcripts to respondents. 


\begin{tabular}{|c|c|c|}
\hline Reporting criteria & $\begin{array}{l}\text { No }(\%) \\
(n=18)\end{array}$ & $\begin{array}{l}\text { References of studies } \\
\text { reporting each criterion }\end{array}$ \\
\hline \multicolumn{3}{|l|}{ Characteristics of research team: } \\
\hline Interviewer or facilitator identified & $16(88)$ & $20-24,26-28,30-37$ \\
\hline Credentials & $12(67)$ & $20,22,24,26-28,30,32-36$ \\
\hline Occupation & $13(72)$ & $22-24,26-28,30,32-37$ \\
\hline Sex & $12(67)$ & $21,23,26,27,29,30-32,34-37$ \\
\hline Experience and training & $11(61)$ & $21,22,24,26,28,31-36$ \\
\hline \multicolumn{3}{|l|}{ Relationship with participants: } \\
\hline Relationship established before study started & $3(17)$ & $24,34,36$ \\
\hline Participant knowledge of interviewer & $10(56)$ & $21-24,26,27,32,34,36,37$ \\
\hline Methodological theory identified & $12(67)$ & $21-24,26-28,30-32,35,36$ \\
\hline \multicolumn{3}{|l|}{ Participant selection: } \\
\hline $\begin{array}{l}\text { Sampling method (for example, snowball, } \\
\text { purposive) }\end{array}$ & $16(88)$ & $20-32,34-36$ \\
\hline Method of approach & $16(88)$ & $20-29,31,33-37$ \\
\hline Sample size & $18(100)$ & $20-37$ \\
\hline Number or reasons for non-participation & $11(61)$ & $21-25,30-32,34-36$ \\
\hline \multicolumn{3}{|l|}{ Setting: } \\
\hline Setting of data collection & $13(72)$ & $20-24,26,29-32,35-37$ \\
\hline Presence of non-participants & $3(17)$ & $21,22,36$ \\
\hline Description of sample & $18(100)$ & $20-37$ \\
\hline \multicolumn{3}{|l|}{ Data collection: } \\
\hline Interview guide & $15(83)$ & $20,22-24,26-36$ \\
\hline Repeat interviews & $4(22)$ & $21,25,34,36$ \\
\hline Audio or visual recording & $16(88)$ & $20,21,23,25-37$ \\
\hline Field notes & $4(22)$ & $23,25,26,34$ \\
\hline Duration & $13(72)$ & $20-22,25,26,28-33,35,36$ \\
\hline Data (or theoretical) saturation & $9(50)$ & $21,22,24-26,28,30,31,36$ \\
\hline Transcripts returned to participants & $0(0)$ & - \\
\hline \multicolumn{3}{|l|}{ Data analysis: } \\
\hline Number of data coders & $12(67)$ & $20,24,26-28,30-35,37$ \\
\hline Description of coding tree & $11(61)$ & $20,22,24,26,28-32,35,36$ \\
\hline Derivation of themes & $16(88)$ & $20,22,24-37$ \\
\hline Protocol for data preparation and transcription & 7 (39) & $20,22,23,26,29,31,35$ \\
\hline Use of software & $7(39)$ & $22,27,29,34-37$ \\
\hline Participants' feedback or member checking & $5(28)$ & $24,25,27,34,36$ \\
\hline \multicolumn{3}{|l|}{ Reporting: } \\
\hline Participant quotations provided & $17(94)$ & $20-30,32-37$ \\
\hline Data and findings consistent & $14(78)$ & $21,22,24,26-28,30-37$ \\
\hline Clarity of major themes & $18(100)$ & $20-33,35-37$ \\
\hline Clarity of minor themes & $11(61)$ & $20-22,25,26,28,30-32,35,36$ \\
\hline
\end{tabular}

\section{Synthesis}

Four major themes were identified as being central to treatment choices: confronting mortality (choosing life or death, being a burden, living in limbo), lack of choice (medical decisions, lack of information, constraints on resources), gaining knowledge of options (peer influence, timing of information), and weighing alternatives (maintaining lifestyle, family influences, maintaining the status quo; fig 2). Table 3 lists the studies that reported or discussed each theme. Table 4 provides a selection of quotes from participants and explanations offered by the authors to illustrate each theme.

\section{Confronting mortality}

The theme confronting mortality encompassed the thoughts, feelings, and attitudes of patients and their families confronting chronic kidney disease as a life threatening illness. Choosing life or death related to patients contemplating palliative care (or rejecting it) and what effect this would have on their family. Being a burden emphasised the feelings patients had about undertaking rigorous renal replacement therapy and the effort others would have to make to support this decision. Living in limbo described the inertia patients and carers felt through not knowing when end stage kidney failure would occur, and the resulting inability to make clear decisions.

Choosing life or death - Most respondents considered the possibility of their own death as they anticipated the future and made personal choices. Some described being startled by the conscious realisation that they could die from their disease. Patients from five studies displayed a preference for palliative management rather than intensive hospital treatments. These patients (mostly elderly) accepted the terminal nature of their disease and were not prepared to make the necessary changes to lifestyle associated with dialysis. Others thought it was not yet their time to die and therefore did not seriously consider refusing treatment. Patients from two studies described chronic kidney disease as an opportunity to re-evaluate life; establish new priorities, such as relationships with family and friends; and reconsider life as a spiritual journey.

Being a burden-The desire not to be a burden on family members was a prominent reason for patients choosing palliative management. Older patients in eight studies talked about the disruption dialysis would have to the lives of their spouse or children.

Living in limbo-Patients receiving dialysis or palliative care referred to the prognostic uncertainty of transplantation or death. Patients talked about not knowing how long they would have to continue with dialysis before a kidney was available and this influenced their decision on whether to go on the waiting list. Patients receiving palliative care were unsure how long they would live, and this made them doubt the medical information they were receiving and to reconsider whether they were making the right choice. They thought that the uncertainty of their prognosis inhibited their ability to make adjustments to their lifestyle, such as selling their assets and moving into assisted care accommodation.

\section{Lack of choice}

The theme lack of choice described the perceived lack of individual choice in decision making about treatment. Medical decisions referred to clinicians excluding a particular treatment option owing to either medical contraindications or physician preference. Lack of information related to patients not knowing about all available treatment options, thereby limiting their choices. Constraints on resources described the patients' and carers' lack of treatment choice owing to the limitations of their treating renal centre. 
Table $3 \mid$ Themes identified in each study

\begin{tabular}{|c|c|c|c|c|c|c|c|c|c|c|c|c|c|c|c|c|c|c|}
\hline \multirow[b]{2}{*}{ Themes } & \multicolumn{18}{|c|}{ Study reference } \\
\hline & 20 & 21 & 22 & 23 & 24 & 25 & 26 & 27 & 28 & 29 & 30 & 31 & 32 & 33 & 34 & 35 & 36 & 37 \\
\hline \multicolumn{19}{|l|}{ Confronting mortality: } \\
\hline Choosing life or death & - & Yes & Yes & Yes & Yes & Yes & - & - & Yes & Yes & - & - & - & Yes & Yes & - & Yes & - \\
\hline Being a burden & - & Yes & - & - & - & Yes & - & - & Yes & - & - & - & Yes & Yes & Yes & Yes & Yes & - \\
\hline Living in limbo & - & Yes & - & - & - & Yes & - & Yes & - & - & - & - & Yes & - & - & - & Yes & - \\
\hline \multicolumn{19}{|l|}{ Lack of choice: } \\
\hline Medical decisions & Yes & Yes & Yes & Yes & Yes & Yes & Yes & Yes & Yes & Yes & Yes & Yes & Yes & - & Yes & Yes & Yes & Yes \\
\hline Lack of information & Yes & Yes & Yes & - & Yes & - & - & Yes & - & Yes & Yes & Yes & - & - & Yes & - & Yes & Yes \\
\hline Constraints on resources & - & - & Yes & Yes & Yes & - & Yes & Yes & Yes & Yes & - & - & Yes & Yes & Yes & - & - & - \\
\hline \multicolumn{19}{|l|}{ Gaining knowledge of options: } \\
\hline Peer influence & - & - & Yes & Yes & Yes & - & Yes & - & Yes & - & - & - & Yes & Yes & Yes & Yes & Yes & Yes \\
\hline Timing of information & - & - & Yes & Yes & Yes & - & Yes & Yes & - & Yes & - & Yes & - & - & Yes & - & Yes & Yes \\
\hline \multicolumn{19}{|l|}{ Weighing alternatives: } \\
\hline Maintaining lifestyle & - & - & Yes & - & - & Yes & - & - & - & - & Yes & Yes & - & - & Yes & Yes & Yes & Yes \\
\hline Family influences & - & Yes & Yes & Yes & Yes & Yes & - & - & Yes & Yes & Yes & Yes & Yes & Yes & Yes & Yes & Yes & - \\
\hline Maintaining the status quo & - & - & Yes & - & - & - & - & - & - & - & Yes & - & - & Yes & Yes & - & - & Yes \\
\hline
\end{tabular}

Medical decisions-Respondents from 17 studies talked of decisions about treatment options being made for them because of either a physiological contraindication such as the inability to create vascular access, or physician preference. Patients from nine of the 18 studies obtained an understanding of treatment options from their nephrologist or renal nurse, and the way this information was framed influenced their decision making. For example, one patient dismissed transplantation after hearing it was "a six hour operation that was a risk between life and death." ${ }^{26}$ Patients and carers from five studies highlighted the difficulty in changing treatment, particularly if they started hospital based haemodialysis but preferred another modality. Some patients willingly accepted a physician led choice of modality, particularly when the rationale was explained to them, and others perceived they had a choice in renal replacement therapy even when they had limited involvement in choosing their treatment.

Lack of information -Eleven of 18 studies reported that patients or their carers did not have the information they wanted on treatment options, regardless of whether transplantation, dialysis, or palliative care was preferred. Family members of patients were especially concerned about their lack of knowledge of the different treatments available and the practicalities in managing each treatment.

Constraints on resources-Ten studies reported that dialysis or transplant resources (such as space at a satellite facility or availability of kidneys) formed the basis of treatment decisions. Limited access to centre based dialysis was a consistent reason for choosing haemodialysis at home or peritoneal dialysis. Patients from three US studies mentioned the importance of having health insurance that paid for dialysis. Patients were generally reluctant to initiate discussions with friends or relatives about living kidney donation but verbalised their desire for a transplant and a place on the deceased donor waiting list. One study reported patients' and carers' preferences for obtaining a kidney transplant commercially rather than waiting for an organ from a deceased donor.

\section{Gaining knowledge of options}

The theme gaining knowledge of options described the ways in which the patients and their carers learnt about treatment options, and the factors influencing their decision making. Peer influence referred to the impact of other patients' experiences on treatment decision making. Timing of information related to the provision of information on treatment options along the trajectory of chronic kidney disease, with reference to other events such as hospital admissions for acute illness or creation of vascular access.

Peer influence-Patients were greatly influenced by the experiences of other patients. They imagined themselves in a similar position (for example, looking really well after transplantation or managing a Tenckhoff catheter) and described being inspired to carry out dialysis themselves. Similarly, some patients dismissed a particular therapy after seeing complications in other patients, such as refusing haemodialysis after seeing a swollen and disfigured arm following a fistula operation.

Timing of information-Ten studies reported the importance of the timing of information on treatment options. Patients recounted being too unwell to take in the information presented or too rushed into making a decision without having time to discuss the options with their families. Information about kidney transplantation was commonly introduced to patients after dialysis had been established. For some patients information about treatment options came after undergoing surgery for vascular access.

\section{Weighing alternatives}

When treatment options were presented, patients' decisions were influenced by a desire to "maintain their pre-existing lifestyle" and were shaped by opinions of family and friends. Once a treatment pathway 


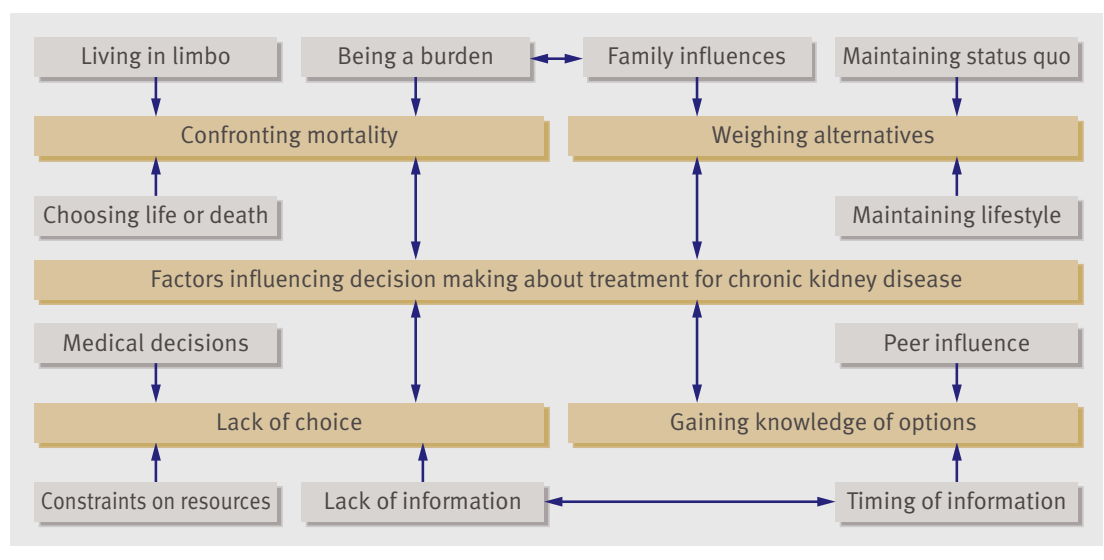

Fig 2 | Components of each theme identified as influencing treatment decisions

was established, patients were reluctant to change the status quo and switch treatments.

Maintaining lifestyle-The medical outcomes of treatment were considered less important than the effect of the treatment on the patient's lifestyle - that is, patients were less concerned about their longevity than they were about their quality of life. Treatment choices were based on minimising disruption to usual activities, upholding responsibilities, and maintaining personal interests. Examples of this included the ability to continue working, maintain a social life, or care for grandchildren (see table 4).

Family influences-Fourteen studies reported that the preferences of the family and carer had a strong influence on patients' choice of treatment. Family influences ranged from support to drive patients to their place of dialysis, offers of living kidney donation, or censoring of information on treatment options not congruent with the family's wishes.

Maintaining the status quo-Patients expressed reluctance to change treatment once it was established, indicating a preference for the status quo. This included switching from haemodialysis to peritoneal dialysis and from dialysis to transplantation. This was particularly evident when a patient had a functioning fistula. Patients verbalised a perceived risk in changing treatments and were fearful of additional surgery or potential complications resulting in infection or death. Many described how they learnt to accept and adjust to the treatment they were on regardless of their initial preference.

\section{Specific preferences for dialysis modality}

When a choice of treatments was offered to patients this was usually between haemodialysis and peritoneal dialysis. Fifteen studies described specific preferences for dialysis modality according to the established themes (table 5).

\section{DISCUSSION}

The four themes that emerged from this synthesis of primary studies (confronting mortality, lack of choice, gaining information about options, and weighing alternatives) were relevant to decision making across all treatments for chronic kidney disease. Many patients perceived they had limited choices in treatment. When choice was offered, preferences for peritoneal dialysis were based around privacy, freedom, and flexibility, whereas preferences for haemodialysis were attributed to a planned schedule, regular social contact, and previous knowledge of the therapy. Patients with a strong preference for transplantation wanted to resume a "normal life," and those who opted for palliative management were not prepared to undertake the rigours of dialysis but wanted supportive end of life care. Overall, patients were less concerned about their longevity with a specific treatment and more concerned about its impact on their quality of life.

\section{Factors influencing decision making}

This synthesis highlighted three major factors that influenced decision making that were over and above the findings from the primary studies alone. The first was the impact of peers on decision making by patients and carers, the second was the problematic timing of information presented, and the third was the desire by patients to maintain the status quo.

\section{Peer influence}

Peer influence was a powerful and persuasive method for patients to gain knowledge of their treatment options. Meeting other patients and listening to their experiences helped patients and their carers to conceptualise the reality of dialysis and transplantation. Peers may have been more influential than clinicians in decision making.

\section{Timing of information}

Participants often reported being too sick to make sense of the information they were given on treatment options: "The doctor might have mentioned it [continuous ambulatory peritoneal dialysis] but I was so sick at the time I didn't catch on to it." ${ }^{22}$ Patients and families also identified needing time to absorb information and to adjust to the approaching treatment regardless of whether they were contemplating a home haemodialysis modality or palliative care.

Research on nephrologist-patient communication suggests that nephrologists provide information on treatment options over an extended period of time but increase the amount of detail about specific treatments when the patient requires renal replacement therapy. ${ }^{38}$ Although this sounds reasonable it is likely that this approach will reduce the time available to patients to make decisions and means that information provision will coincide with the patient becoming symptomatic or cognitively impaired. From a patient's perspective this practice of increasing discussions about treatment options when end stage kidney disease is approached is inadequate for decision making. ${ }^{3940}$ Guidelines for chronic kidney disease from the UK and kidney disease quality outcomes initiative recommend counselling for treatment options six months before the onset of established renal failure. ${ }^{3940}$ These same guidelines, however, also recommend that a 
Table 4 | Quotations from participants and authors of primary studies to illustrate each theme

Confronting mortality

I see it as a natural course. You see, I have no loyalty. I mean my children are grown up now and the have got their husbands and their children. And there is nothing to make me think oh I had bette stay around ${ }^{21}$

Choosing life or I got too much going... I've been married 12 years and l've got two little girls. There was no death question 36 Once I went through the fact that I had no choice, it was either that or die-it was either haemo, peritoneal or die. Those were my three choices. And it was like, "Oh"36

Being a burden No like I said when we came home we sat down and had a talk, just Alice and meself there and we thought about it, I thought about it and ah, I didn't want to go on that dialysis to be a burden to Alice. You know three days a week and five hours or whatever. And I say I didn't want to put that on her because she had enough putting up with me as it was ${ }^{21}$

Living in limbo They can't tell you, you know, how long you have to go. You see this is quite true, they don't know. With all the modern stuff and all that, they still don't know ${ }^{21}$

Patients over 77 years of age tended to see dying as a natural course that they would prefer to take, rather than to burden their children with issues relating to dialysis $^{21}$

Love and responsibility for family members gave many patients meaning and purpose in continued survival ${ }^{36}$

Acceptance of kidney failure permitted patients to face reality and move on ${ }^{36}$

The desire not to be a burden was a prominent contributory reason for patients choosing not to start dialysis. Patients expressed concern about the disruption that dialysis would cause to their family life ${ }^{21}$

Prognostic unpredictability affected those who were receiving palliative care. Each expressed desire for their deaths to come quickly and be pain free ${ }^{21}$

Lack of choice

I asked him [doctor] about did he ever sign me up for a transplant and he said he couldn't cause my kidneys has hardened and there was no use to try to go in with no transplant ${ }^{26}$

Physiologically dictated decision—a patient's physiological limitations dictated modality choice 2226

Well it looks like I'm going to have to have the stomach one because the fistulas are just not working. I've had three ${ }^{34}$

Medical decisions Since he [nephrologist] owned four haemodialysis units, his suggestion was that I go on haemo ${ }^{30}$

The only thing the doctor said was that I was going to be on dialysis. I didn't know it was like this. I didn't have a choice. He didn't say you have choices of dialysis, which one would you like? I was told the one. I was going to be on this machine. That's it ${ }^{22}$

When I went on dialysis I was automatically put on haemodialysis. I was not even told about CAPD [continuous ambulatory peritoneal dialysis] ${ }^{22}$

Lack of information They don't tell you everything you need to know ... ${ }^{20}$

I just took the pills (prednisolone) and I was told a few things, but not, I don't feel nearly enough things. I was not aware of the fact that your vision could be affected ${ }^{36}$

I tried to get in to GS [another facility] but they were booked up and there were no openings, but there was an opening here ${ }^{22}$

I'm going to get a kidney transplant from a relative ${ }^{26}$

Some patients willingly accepted a physician led decision on modality ${ }^{30}$

Patients perceived they had a choice in renal replacement therapy even when they had limited involvement in choosing their treatment ${ }^{26}$

Some patients thought there was no patient choice in decision making on modality $^{22}$

The lack of information in patient education sessions affected patient's quality of life ${ }^{20}$; patients who preferred a more autonomous or collaborative decision making process wanted more information ${ }^{36}$

Access rationing decision: the patients' stated choice of modality was based on factors such as availability at a dialysis centre ${ }^{22}$

Usually dialysis was presented as an option first, then transplant once dialysis was established ${ }^{27}$

Constraints on

resources

The day I found out that my kidneys had failed, uh, the doctors there told me that I would have to go on dialysis and uh, they asked me would you want a kidney transplant. And I said, yes I would, cause I didn't want to do this all my life. So, I told them put me on the list ${ }^{26}$

Gaining knowledge of options

Another woman was at the unit where I was on dialysis, and she was on CAPD [continuous ambulatory peritoneal dialysis]. She told me about it and I knew this was something I wanted to $\mathrm{do}^{22}$

Peer influence I saw people on home HD [haemodialysis] and they looked better ${ }^{24}$ Physicians recommended home haemodialysis when there was no close incentre haemodialysis. Patients also chose home haemodialysis based on long distance from home to a centre. One patient stated that he did not want to ride the bus to another town and spend so much time travelling ${ }^{23}$

Just by listening to [other patients] and talking to them and they tell me how things go and all that, that is really helpful ${ }^{36}$

The doctor might have mentioned it [continuous ambulatory peritoneal dialysis] but I was so sick at the time I didn't catch on to it. My response was that if had been told about something like that, I would have wanted to go with it $^{22}$

Timing of information

I received the book (Kidney Foundation of Canada, 1999), which explained things quite well. But [I] didn't absorb the information. [It was] difficult to grasp ${ }^{24}$

Patients were influenced greatly by other patients ${ }^{22}$; other patients were especially important as role models ${ }^{36}$

Patients identified needing time to absorb information and adjust to the approaching dialysis ${ }^{24}$; patients and carers stated that it took time to find their own way of handling a chronic disease ${ }^{37}$; decisions are often made under highly stressful, and physically demanding situations when patients are sick. Often made rapidly, without enough time to consider options properly ${ }^{27}$; seven of 12 patients receiving haemodialysis stated that they were too sick to make a decision and that the decision had been made for them during hospital stay ${ }^{31}$

Weighing alternatives My husband disagreed with the treatment. He was too busy to take me to the hospital ${ }^{28}$

Families exerted pressure on the patients to choose the modality that best suited the family members' desires ${ }^{30}$

I discussed the decision with my husband, and he said the CAPD [continuous ambulatory peritone dialysis] was better for me because I could still do housework at home $\mathrm{e}^{35}$

My husband has to be able to accept it [home haemodialysis]. If he can't, then we won't do it ${ }^{37}$

Family members were especially interested in ways to expand their roles to better support patients. They were also more likely than patients to have internet access $^{29}$

Relatives felt the decision to dialyse affected their lives too $^{37}$

One of the first reactions I had was "How am I going to keep my job?" I go to work and then have to leave probably by noon three days a week, l'm only going to put in half a day of work. This is not

Maintaining

lifestyle to work for me and I'm sure its not going to work for my employer

I have a son and I would have to go to the hospital every other day for haemo. It was real hard for me. With peritoneal, I could be in my own surroundings at home $\mathrm{s}^{30}$

They had to put me right away on dialysis. They explained to me about the other one [continuous ambulatory peritoneal dialysis] but I liked this one better. I prefer this one [in-centre haemodialysis] ${ }^{22}$

Maintaining the I felt like the machine saved my life and since that was already doing the job, I didn't feel like crossing over [switching modalities]. I think in the beginning, the one you start with has a lot to do with it ${ }^{30}$

Medical effectiveness was less important than the effect of treatment on the course of patients' lives ${ }^{25}$

This man felt like acute haemodialysis had saved his life and therefore wanted to stay with it. Switching may have been a risk ${ }^{30}$; some patients stay with haemodialysis because they already have a fistula (vascular access) created and don't want to risk further surgery ${ }^{30}$; patients felt a sense of security obtained from familiarity ${ }^{37}$ 


\section{Table 5|Patients' and carers' preferences for dialysis modality}

\begin{tabular}{|c|c|}
\hline Modality and reasons for choosing or not choosing modality & Participants' quotes \\
\hline \multicolumn{2}{|l|}{ Peritoneal dialysis } \\
\hline \multicolumn{2}{|l|}{ Reasons for choosing modality: } \\
\hline Self capability $v$ depending on care from strangers & I like taking responsibility for my own care $\ldots{ }^{20}$ \\
\hline Managing illness in privacy of own home & With haemodialysis there's no partition, no privacy. I couldn't even meditate ${ }^{36}$ \\
\hline More freedom or flexibility & $\begin{array}{l}\text { "Mainly because it [peritoneal dialysis] gives me a little bit more freedom. Being able to do it at home I wouldn't have to } \\
\text { come to the hospital }\end{array}$ \\
\hline Less time in hospital & I am a pharmacist ... worked eight hours in the hospital. I did not want to spend the rest of my time in hospital again ${ }^{35}$ \\
\hline Ability to travel & $\begin{array}{l}\text { It would allow me if I wanted to take a trip, to go somewhere and basically do it myself, instead of having to try to find a } \\
\text { facility that could accommodate } \mathrm{me}^{22}\end{array}$ \\
\hline Ability to continue part time work & $\begin{array}{l}\text { I need flexibility to go where the meetings are and to get up and move around. CAPD [continuous ambulatory peritoneal } \\
\text { dialysis] seemed like it would allow me to function in those capacities }{ }^{30}\end{array}$ \\
\hline Ability to continue care giving for children & $\begin{array}{l}\text { I have a son and I would have to go to the hospital every other day for haemo. It was real hard for me. With peritoneal, I } \\
\text { could be in my own surroundings at home } \mathrm{s}^{30}\end{array}$ \\
\hline \multicolumn{2}{|l|}{ Reasons for not choosing modality: } \\
\hline Concerns about having Tenckhoff catheter & $\begin{array}{l}\text { It makes me feel uncomfortable to see that thing that comes out of your stomach. It gives me a funny feeling like someone } \\
\text { scratching a chalkboard }{ }^{30}\end{array}$ \\
\hline Concerns about sterility in home and getting an infection & Peritoneal dialysis is sterile and can't be done at my home ${ }^{26}$ \\
\hline Inability to store dialysis supplies & $\begin{array}{l}\text { Where we were living previously there was no space [for peritoneal dialysis supplies]. We couldn't get one iota of anything } \\
\text { else in that place } 36\end{array}$ \\
\hline \multicolumn{2}{|l|}{ Haemodialysis } \\
\hline \multicolumn{2}{|l|}{ Reasons for choosing modality: } \\
\hline Liked others caring for them & $\begin{array}{l}\text { I know we couldn't do CAPD [continuous ambulatory peritoneal dialysis]. No, I sooner trust the girls, because they're } \\
\text { supposed to know about it }{ }^{30}\end{array}$ \\
\hline Preferred a planned schedule & Since I usually control the scheduling of my job, the time to spend in the hospital is OK for me $\mathrm{e}^{35}$ \\
\hline Free days with no dialysis & $\begin{array}{l}\text { [Haemodialysis] would be less disruptive of our life. Two, three hours a day, every other day, and then you can go on with } \\
\text { your life in between times }{ }^{25}\end{array}$ \\
\hline Perception of haemodialysis as a "better" therapy & I suppose the blood one is probably the proper one, I don't know ${ }^{34}$ \\
\hline Previous knowledge of haemodialysis from family member & I decided to take it with the machine because I already knew what it was like $\mathrm{e}^{30}$ \\
\hline Could go swimming & $\begin{array}{l}\text { You can't go swimming with that damn thing [peritoneal dialysis catheter]. This way, I don't have no openings, I can go } \\
\text { swimming anytime I want, I don't have to worry about dirty water or whatever getting into it }{ }^{30}\end{array}$ \\
\hline Convenience & The haemodialysis centre's right close to my home. It's real convenient ${ }^{36}$ \\
\hline \multicolumn{2}{|l|}{ Reasons for not choosing modality: } \\
\hline Needle phobia & $\begin{array}{l}\text { There's a big machine and you see blood and for me its scary. With haemo there's more needles involved, its more } \\
\text { dangerous }{ }^{30}\end{array}$ \\
\hline Looking like a "patient" & $\begin{array}{l}\text { My mother said that having a fistula on the arm would show I was a patient. However, with an abdominal catheter on the } \\
\text { belly people would not know ... }\end{array}$ \\
\hline Fear of cross infection & $\begin{array}{l}\text { Haemo is pretty dangerous because you don't know whose blood is where. What assurance would I have that somebody } \\
\text { else's blood was not in the machine somewhere }\end{array}$ \\
\hline
\end{tabular}

native arteriovenous access be created six months before end stage renal disease. ${ }^{3940}$ There are several potential consequences of having a fistula created before a full discussion of treatment options. Firstly, patients risk having surgery for a treatment they do not wish to pursue. Secondly, our analysis suggests that the creation of vascular access may mean that a patient believes a treatment choice has already been made for them.

\section{Maintaining the status quo}

When weighing up alternatives for treatment, patients are reluctant to change treatments despite the potential advantages - that is, doing nothing or maintaining a current or previous decision is preferable to change. ${ }^{4142} \mathrm{It}$ seemed that maintaining the status quo, which was usually continuing with hospital based haemodialysis, was preferable for many patients rather than risking a change to a different treatment. Once vascular access was created, patients were especially reluctant to consider other treatments, even to accept a kidney transplant. Although creation of vascular access may be considered a good back-up regardless of treatment preference, to a patient it can be perceived that a treatment choice has been made thereby limiting their consideration and choice of peritoneal dialysis, pre-emptive transplant, or palliative care: "Oh well they, the doctor I was seeing at the time over there sort of knew I was a bit iffy (about haemodialysis) ah, but I think when I agreed to have the fistula put in my arm she might have thought I was saying yeh I'd do it." 34

\section{Strengths and limitations of the review}

This study incorporated the experiences of decision making in all treatment options for chronic kidney disease, including palliative care, transplantation, and dialysis, and used rigorous methods for systematic review that included a comprehensive search of published and unpublished studies using predetermined criteria. This review also included the findings from relevant 


\section{WHAT IS ALREADY KNOWN ON THIS TOPIC}

One third of patients with chronic kidney disease receive information about treatment options after starting dialysis, contrary to current clinical guidelines

For patients, lifestyle considerations rank higher than medical consequences of specific treatments in their decision making

\section{WHAT THIS STUDY ADDS}

Thematic synthesis of qualitative studies is valuable in understanding patients' perspectives and can inform practice and policy

The problematic timing of information about treatment options and synchronous creation of vascular access may predetermine the use of haemodialysis and limit choice of other treatments, including palliative care

Patients have a strong preference for the status quo and are reluctant to change treatments, which may help explain why patients often continue with their initial therapy

chapters of three unpublished $\mathrm{PhD}$ theses. Study reporting was assessed according to a published framework, ${ }^{17}$ which allowed readers to judge for themselves the quality of included studies and generalisability to their own context. We combined eligible studies of experiences in treatment decision making from patients' and carers' perspectives in a deliberate attempt to achieve the higher level analytical abstraction that is aimed for in thematic synthesis. Despite different contexts, our themes, developed from the experiences of 462 participants, indicated considerable overlap from each of the primary studies.

We used previously applied methods for systematic reviews of patients' experiences and perspectives to synthesise findings, emphasising transparency in the development of descriptive and analytical themes. ${ }^{18444}$ Comprehensive details were provided about the primary studies including research team characteristics, participants, settings, and methods as reported by the authors of each study. We found the primary studies that were more comprehensive in their reporting contributed most to the final analytical themes. The review was limited to the experiences of participants in the included primary studies and underrepresented people from non-English speaking backgrounds and those seeking palliative care. We were unable to ascertain the level of literacy of most study participants and therefore cannot make any conclusions regarding experiences in decision making about treatment within the context of low literacy. The findings may not be generalisable to patients and carers elsewhere; however, the analytical themes offer a higher level of conceptual thinking about decision making that may be applicable across different contexts.

\section{Implications of the review}

Several strategies to improve patient care could be implemented immediately as a result of this synthesis. Firstly, the formal incorporation of peers (other patients) with chronic kidney disease as mentors or educators into the "orientation" of new patients to the renal unit may be beneficial. Secondly, the rewording of clinical practice guidelines for optimal timing of education about treatment options should be updated to recommend giving information at stage 4 disease when the estimated glomerular filtration rate first drops below $30 \mathrm{ml} / \mathrm{min} / 1.73 \mathrm{~m}^{2}$, well before the creation of access for dialysis. Thirdly, formal care pathways for pre-emptive transplantation and home dialysis (both haemodialysis and peritoneal dialysis) as well as for palliative management for patients not wishing to dialyse should be developed, such that patients can start renal replacement therapy outside an acute haemodialysis centre, to facilitate provision of treatments more aligned with their preferences.

As a result of the paucity of data in renal palliative care, further research, such as that being done in the $\mathrm{UK},{ }^{45}$ is required to inform clinicians about the needs of the growing cohort of elderly patients who choose not to have dialysis. Qualitative research would provide valuable insight into the effectiveness of formal palliative care pathways from the perspective of patients, carers, and clinicians. A randomised controlled trial comparing modes of education could provide definitive answers about the effects of peer education for new patients. In addition, research that specifically deals with the views of culturally and linguistically diverse people regarding decision making about treatment is needed. The role of qualitative research in evidence based medicine has become clearer in recent years. ${ }^{4647}$ Synthesis of qualitative studies can provide evidence to research questions concerning patients' or practitioners' experiences (what works, for whom, and under what circumstances), opportunities for and barriers to improvement (including issues of access or acceptability), and an explanation of the associations between interventions and outcomes. ${ }^{47}$

\section{Conclusions}

This thematic synthesis of qualitative studies on decision making about treatment for chronic kidney disease shows that the requirements of many patients and their carers are not being met. Factors influencing treatment decisions included the experiences of other patients (peer influence); the problematic timing of information about treatment options and synchronous creation of vascular access, which appeared to predetermine haemodialysis and inhibit choice of other treatments (including palliative care); and a preference to maintain the status quo may explain why patients often continue with their initial therapy.

Contributors: RLM designed the study, undertook the systematic review, carried out the thematic synthesis, and wrote the manuscript. AT participated in the design of the study and systematic review, provided guidance in the thematic synthesis, and reviewed the manuscript. KH participated in the design of the study, presentation of results, and critical review of the manuscript. PS participated in the design of the study, interpretation of the results, and critical review of the manuscript. ACW participated in the design of the study and systematic review, interpretation of the results, and critical review of the manuscript. RLM and $\mathrm{AT}$ are the guarantors.

Funding: RLM is supported by the National Health and Medical Research Council grants in population health (Nos 457281 and 571372).

Competing interests: None declared.

Ethical approval: Not required. 
Data sharing: A full list of participants' quotes and explanations offered by the authors to illustrate each of the four themes are available on request from the corresponding author at rachaelm@health.usyd.ed.au.

1 Hornberger JC, Habraken H, Bloch DA. Minimum data needed on patient preferences for accurate efficient medical decision making. Med Care 1995;33:297-310.

2 Greenfield S, Kaplan S, Ware JE. Expanding patient involvement in care: effect on patient outcomes. Ann Intern Med 1985;102:520-8.

3 Roter DL, Hall JA. Studies of doctor-patient interaction. Annu Rev Public Health 1989;10:163-80.

4 Ansell D, Feehally J, Feest TG, Tomson C, Williams AJ, Warwick G. New adult patients starting renal replacement therapy in the UK in 2006. In: UK Renal Registry, ed. UK Renal Association, 2007:17-47.

5 Mehrotra R, Marsh D, Vonesh E, Peters V, Nissenson A. Patient education and access of ESRD patients to renal replacement therapies beyond in-center hemodialysis. Kidney Int 2005;68:378-90.

6 US Renal Data System. The USRDS Dialysis Morbidity and Mortality Study: wave 2 In: National Institute of Diabetes and Digestive and Kidney Diseases, ed. USRDS 1997 annual data report. National Institutes of Health, 1997:49-68.

7 Nissenson AR, Prichard SS, Cheng IKP, Gokal R, Kubota M, Maiorca R, et al. Non-medical factors that impact on ESRD modality selection. Kidney Int 1993;43(suppl 40):120-7S.

8 Heaf J. Underutilization of peritoneal dialysis. JAMA 2004;291:740-2.

9 Ozminkowski R, White A, Hassol A, Murphy M. What if socioeconomics made no difference? Access to cadaver kidney transplant as an example. Med Care 1998;36:1398-406

10 Boulware LE, Meoni LA, Fink NE, Parekh RS, Kao L, Klag MJ, et al. Preferences, knowledge, communication and patient-physician discussion of living kidney transplantation in African American families. Am J Transplant 2005;5:1503-12.

11 Higgins RS, Fishman JA. Disparities in solid organ transplantation fo ethnic minorities: facts and solutions. Am J Transplant 2006;6:2556-62.

12 Campbell R, Pound P, Pope C, Britten N, Pill R, Morgan M, et al. Evaluating meta-ethnography: a synthesis of qualitative research on lay experiences of diabetes and diabetes care. Soc Sci Med 2003;56:671-84.

13 Noblit GW, Hare RD. Meta-ethnography: synthesizing qualitative studies. Sage, 1988.

14 Sandelowski M, Trimble F, Woodward EK, Barroso J. From synthesis to script: transforming qualitative research findings for use in practice. Qual Health Res 2006;16:1350-70.

15 Zimmer L. Qualitative meta-synthesis: a question of dialoguing with texts. J Adv Nurs 2006;53:311-8.

16 Levey AS, Atkins R, Coresh J, Cohen EP, Collins AJ, Eckardt K-U, et al. Chronic kidney disease as a global public health problem: approaches and initiatives-a position statement from Kidney Disease Improving Global Outcomes. Kidney Int 2007;72:247-59.

17 Tong A, Sainsbury P, Craig JC. Consolidated criteria for reporting qualitative research (COREQ): a 32-item checklist for interviews and focus groups. Int I Qual Health Care 2007;18:349-57.

18 Thomas J, Harden A. Methods for the thematic synthesis of qualitative research in systematic reviews. BMC Med Res Methodol 2008;8:45. www.biomedcentral.com/1471-2288/8/45.

19 Lucas PJ, Baird J, Arai L, Law C, Roberts HM. Worked examples of alternative methods for the synthesis of qualitative and quantitative research in systematic reviews. BMC Med Res Methodol 2007:7:4. www.biomedcentral.com/1471-2288/7/4.

20 Bass EB, Jenckes MW, Fink NE, Cagney KA, Wu AW, Sadler JH, et al. Use of focus groups to identify concerns about dialysis. Med Decis Making 1999;19:287-95.

21 Ashby M, op't Hoog C, Kellehear A, Kerr PG, Brooks D, Nicholls K, et al. Renal dialysis abatement: lessons from a social study. Palliat Med 2005;19:389-96.

22 Breckenridge DM. Patients' perceptions of why, how, and by whom dialysis treatment modality was chosen. ANNA / 1997;24:313-9, 20

23 Courts NF. Psychosocial adjustment of patients on home hemodialysis and their dialysis partners. Clin Nurs Res 2000;9:177-90.
24 Harwood L, Locking-Cusolito H, Spittal J, Wilson B, White S. Preparing for hemodialysis: patient stressors and responses. ANNA J 2005;32:295-302.

25 Kelly-Powell ML. Personalizing choices: patients' experiences with making treatment decisions. Res Nurs Health 1997;20:219-27.

26 Landreneau KJ, Ward-Smith P. Perceptions of adult patients on hemodialysis concerning choice among renal replacement therapies. ANNA / 2007;34:513-9, 25.

27 Landreneau KJ, Ward-Smith P. Patients' perceptions concerning choice among renal replacement therapies: a pilot study. ANNA J 2006;33:397-402

28 Lin C-C, Lee B-O, Hicks FD. The phenomenology of deciding about hemodialysis among Taiwanese. West J Nurs Res 2005;27:915-29.

29 Trisolini M, Roussel A, Zerhusen E, Schatell D, Harris S, Bandel K, et al. Activating chronic kidney disease patients and family members through the internet to promote integration of care. Int I Integr Care 2004:4:1-13.

30 Whittaker AA, Albee BJ. Factors influencing patient selection of dialysis treatment modality. ANNA / 1996;23:369-75.

31 Wuerth DB, Finkelstein SH, Schwetz O, Carey H, Kliger AS, Finkelstein FO. Patients' descriptions of specific factors leading to modality selection of chronic peritoneal dialysis or hemodialysis. Perit Dial Int 2002;22:184-90.

32 Leung SSH, Shiu ATY. Experience of Hong Kong patients awaiting kidney transplantation in mainland China. J Nurs Healthcare Chronic Illnesses 2007;16(suppl 11c):341-9. doi: 10.1111/j.1365-2702.2007.02070.x.

33 Waterman AD, Stanley SL, Covelli T, Hazel E, Hong BA, Brennan DC. Living donation decision making: recipients' concerns and educational needs. Prog Transplant 2006;16:17-23.

34 Fetherstonhaugh D. Hobson's choice: dialysis or the coffin. A study of dialysis decision making amongst older people. PhD thesis, University of Melbourne, 2007.

35 Chen M-C. The experiences of ESRD patients' decision-making process and adaptation to a dialysis treatment modality in Taiwan. Catholic University of America, 2007.

36 Feild ML. Patient decision-making regarding life-sustaining treatment for end-stage renal disease. Boston College, 1996.

37 Lee A, Gudex C, Povlsen JV, Bonnevie B, Nielsen CP. Patients' views regarding choice of dialysis modality. Nephrol Dial Transplant 2008;23:3953-9.

38 Gordon EJ, Sehgal AR. Patient-nephrologist discussion about kidney transplantation as a treatment option. Adv Ren Replace Ther 2000;7:177-83.

39 Taal M, Thomson C. Clinical practice guidelines module 1-CKD. In UK Renal Association, ed. 2007. www.renal.org/guidelines/ module1.html.

40 National Kidney Foundation. Kidney Disease Outcomes Quality Initiative (K-DOQI): clinical practice guidelines for hemodialysis adequacy. National Kidney Foundation, 2006.

41 Samuelson W, Zeckhauser R. Status quo bias in decision making. J Risk Uncertain 1988;1:7-59.

42 Salkeld G, Ryan M, Short L. The veil of experience: do consumers prefer what they know best? Health Econ 2000;9:267-70.

43 Harden A, Garcia I, Oliver S, Rees R, Shepherd I, Brunton G, et al. Applying systematic review methods to studies of people's views: an example from public health. J Epidemiol Community 2004:58:794-800

44 Huberman AM, Miles MB. Handbook of qualitative research. Sage, 1994.

45 Murtagh FEM. Understanding and improving quality of care for people with conservatively managed stage 5 chronic kidney disease -the course of symptoms and other concerns over time. Department of Palliative Care, Policy, and Rehabilitation, King's College London, 2008.

46 Cochrane Qualitative Research Methods Group. The Cochrane Collaboration. 2009. www.joannabriggs.edu.au/cqrmg/role.html.

47 National Institute for Health and Clinical Excellence. Methods for the development of NICE public health guidance. 2009. www.nice.org. uk/media/2FB/53/PHMethodsManual110509.pdf.

Accepted: 30 September 2009 